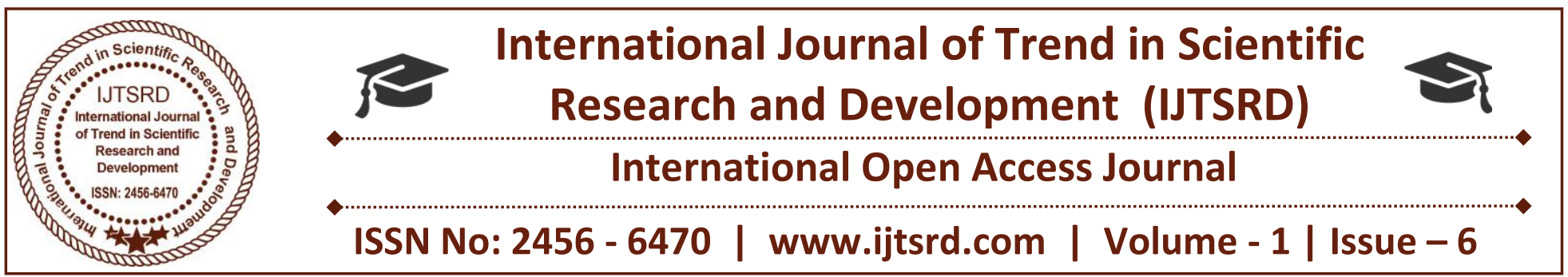

\title{
Cloud Computing
}

Shubhangi Sahare

Department of Electronics \& Tele-Communication Government College of Engineering, Chandrapur,

Maharashtra, India
Dr.D.V.Rojatkar

Department of Electronics \& Tele-Communication Government College of Engineering, Chandrapur442406, Maharashtra, India

Cloud Computing is the most advanced technical platform for next generation. Cloud Computing provide us a wide range of data storage space in web source. Cloud Computing work automatically as per the need of user we don't need to do extra work on it. High level applications and game is run by Cloud Computing. Cloud Computing is not only limited for storage purpose it is more than our imagination. In Cloud Computing we can accesses the application, modified the application over the internet. Cloud Computing cover the wide range of areas. It provides its service through online net connection. Cloud Computing provides tremendous value to every company and business management.

\section{Keywords: Cloud Computing}

\section{INTRODUCTION:}

We all have known about the structure of cloud. It is made up of some water vapours and water molecules and its form a cloud .clouds are never constant at one place it is always moving and covers wide range of area in technical language we can say that cloud is a collection of networks .it is internally connect with each other. After that they form connection with user with the help of internet connection. Users are not constant sometimes user is the or it's not cloud service provide a storage sometime it will be free or it is also chargable.

Figure 1: Structure of cloud

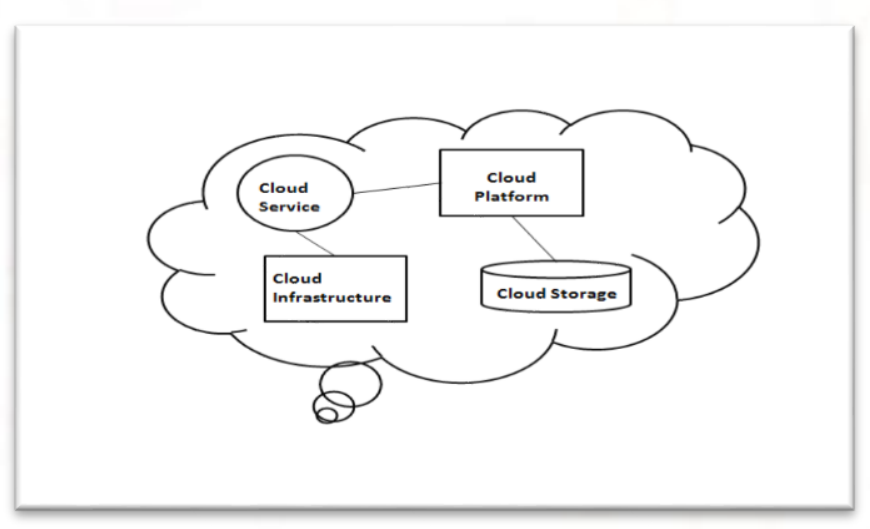

\section{CLOUD COMPUTING:}

Cloud computing provides a online data storage where we can store our maximum data. We want to store our data but we don't want to keep it with us because it may consume more space so we have better option "Cloud Computing" here we can save it. We need to do only registration only. Application of Cloud Computing is not only limited till to store data we can use it in high level game and another various application also. Cloud Computing is a combination of hardware and software. Gmail, one drive, skype are the examples of cloud computing. Let's take an example of gmail when we send message to anyone and check for next time. We get that message was at same place. We don't need to store it on any storage device. Whenever we want it, it is present at that place. This is possible from anywhere and anytime .You can control it from your laptop, Pc's, cellphones, what we want only login id and pass word. 


\subsection{Types of Cloud Computing:}

There are four types of Cloud Computing. Is not constant with four as the service becomes more advanced it's also increase. In future the types of Cloud Computing will be more than four. Followings are type of Cloud Computing.

- Public cloud

- Private cloud

- Community cloud

- Hybrid cloud

\subsubsection{Public Cloud:}

In public cloud, it's a common data storage for all .Any one can use this. It is not limited with specific person. The cloud server provide this service to everyone .but for this you must know the link or address the specific site.

eg:- Google .com

\subsection{Private Cloud:}

In private cloud, it's a limited between the host and user. the servers will provide you a space for store the data and it will be secure by your login id and password without your id and password no one can use your it hear it will be more secure than public Cloud Computing .private cloud is handle by host or company own.

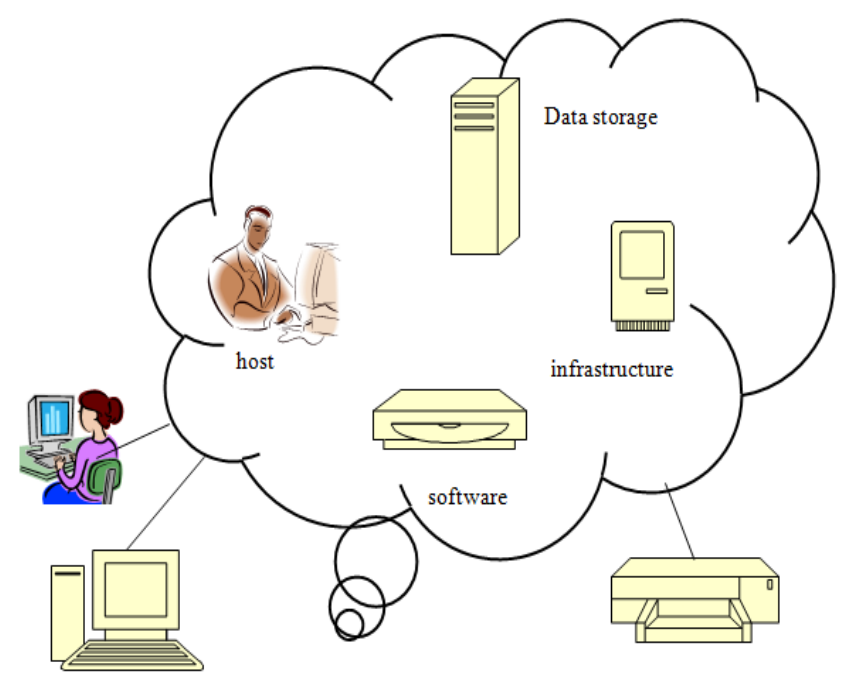

Figure 2: Private Cloud Computing

\subsubsection{Community Cloud:}

In community cloud, it's is for specific group or community. Let's take the example of any college .suppose the college having wifi connection then the student belongs from that college only use this wifi. The person who is not connected from that college they will not allow them for surfing net .which means that it is only limited between only college students. We can say that only the group of that particular college student use this. Here also provide the login id and password for only the group of people.

\subsubsection{Hybrid Cloud:}

Hybrid cloud is a combination of two or more than two cloud. Like public \&private, Private \& Community, or it may be Private, Public \& Community. The solution of hybrid Cloud Computing is available in both cloud computing private and own data center. In hybrid cloud computing suppose it is the combination of two private and public computing then the critical activity performed by using private cloud and non critical by using public cloud

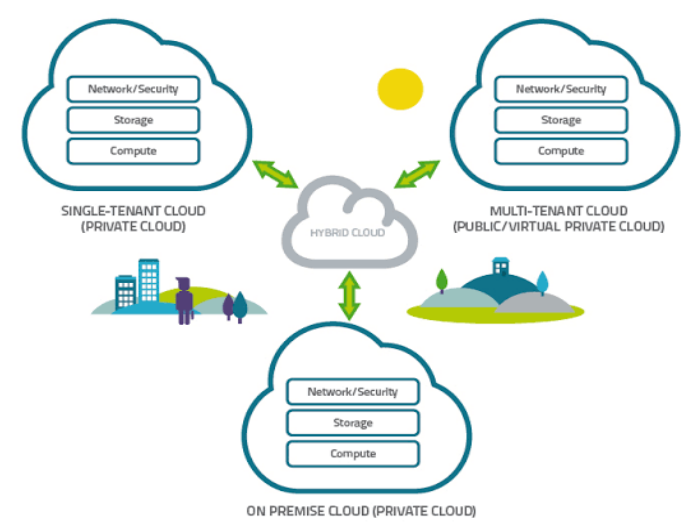

Figure 3: Hybride Cloud Computing

\section{CLOUD COMPUTING SERVIVE:}

Cloud computing is mainly used in business. The coast of this service is cheaper as compare to any hardware data storage management .Cloud Computing service contain following types.

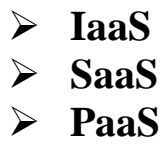

\subsection{Iaas- Infrastructure as a Service:}

In this service it include three main parts I, e is host or serv.er, Individual, business. 
The company provide you some space it is free or chargable depend on the company. Some time it is free upto some specific GB after this for more storage it will chare some money. As a individual or as customers you can work on hardware part and software part on your own risk. Which is use in your business .It is a limited for specific duration and time. it is online service. hear user can run any application on its own risk

\subsection{Saas-Software as a Service:}

In this software service its allow the users to use the software application. This service is accessible via internet. Here everything is store in web we must need to update our system. In Cloud Computing it will be done automatically. For more understanding let's take example of cell phone if we want to run any application .first we want to download it install it and then it will run. it is consume the space of device. Lets the example of the well known social application facebook if we want to make video call to anyone we must do the press on calling key we don't need to download any video calling application . And will not consume our space. In saas it is store in web. And it will run by any location.

\section{3. Paas-Platform as a Service:}

In this service it is provide a platform and storage where you can make your own application and sell it. In this user not need to purchase the high level of hardware and data storage. The example of paaS is

Google's App Engine,Force.com . you need to work in that level of programining .if you choose the any intrest of aea in saaS. Then you need to work on that particular area only. For this you must need to find any vendors. There is an issue to maintain a secure connection in Pass.

\section{METHODOLOGY:}

In this section it contain two parts i.e front end and back end. In back end it contains the all about software portion and in front end it contain it will interface with graphical interface. More easy to use .more easy to sell .if you want to on flash light then you don't want to do any programming for this as to being an user you want to press and use. Here we use some set of programs which is known as protocols. In back end it consist of some cloud which is connected by networks its is only used by internet connection only it required high speed connections in back it contain servers, computers servers and remote controls are do most work and c store data.

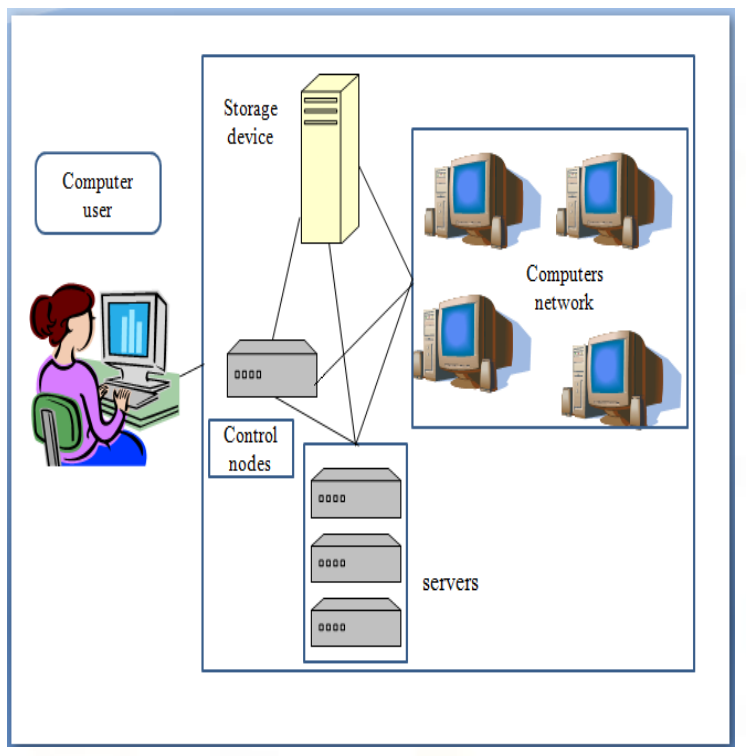

Figure 4: Working of Cloud Computing

\subsection{Need of Cloud Computing}

1. It will reduce the cost we don't need to purchase extra Hardware things for storage.

2. It has the automatic updating service and application.

3. Since it is in control under internet .we don't need to concentrate on technical issue or issues like backup storage.

4. Main need of Cloud Computing is storing a data.

\subsection{Advantage of Cloud Computing:}

1. We can handle it from any time anywhere on any device.

2. Its store our data on web, so we don't need consume our space for downloading any application we can directly used it on web.

3. Cloud Computing will provide a platform to user to make their own application and we can sale it.

4. No need of software. To run any app it's already in web storage

\subsection{Disadvantages of Cloud Computing:}

1. it required fast internet connection

2. some time it will work slow even there is fast internet connection

3. there is some security issue in Cloud Computing 


\section{CONCLUSION:}

This paper shows a general overview of Cloud Computing Software that are masterminded by their expected services. It also covers the survey of various technologies which emphatically support the technical systems in reliable way. In future the Cloud Computing will be most widely used software technology throughout the world. It reduces the coast of extra storage hardware. Cloud Computing is mostly used in business as the owner of any business we can focus on our main business instead of concentrate where we want to store devices. In future there will be more new inventions discovered with help of Cloud Computing.

\section{ACKNOWLEDGEMENT:}

It is with the feeling of great pleasure that I would like to express my most sincere heartfelt gratitude to $\mathbf{D r}$ D.V. Rojatkar for encouraging me to do this work.

\section{REFERENCES:}

1) Mladen .A.Vouk ,Cloud Computing -Issues, Research an Implementations , Informati on Technical Interfaces ,june 2008

2) Rajkumar Buyya,Introduction to the IEEE Transactions on Cloud Computing,January-June 2013.

3) Von Lasewski , Gregor,et al." Comparison of Multiple Cloud frameworks.' IEEE $5^{\text {th }}$ International conference on Cloud Computing,2012

4) Danielson ,Krissi”Distinguish Cloud Computing from utlity computing"Eiz.net 2010

5) Mao ,Ming; M .Humphrey(2012) “A performance study on vm startup Time in the cloud"IEEE $5^{\text {th }}$ International conference on CLOUD COMPUTING ,2012

6) Marston ,Sean ;Li ,Zhi; Bandyopadhyay ,Subhajyoti; Zhang juheng "CLOUD COMPUTING-THE BUSINESS PRESPECTIVE"'(2011)

7) Ananich ,Anthony "What is IaaS ?"(2016)

8) "Hamdaqa Mohammad .A reference model for developing cloud Applicatation

9) Chou ,Timothy .Introduction of Cloud Computing: Business \& Technology

10) Foley, John.'Private clouds take shape" information week retrived, 2010 